\title{
Correction to: Screening for posttraumatic stress disorder in ARDS survivors: validation of the impact of event Scale-6 (IES-6)
}

Megan M. Hosey ${ }^{1,9}$, Jeannie-Marie S. Leoutsakos ${ }^{2}$, Ximin Li ${ }^{3}$, Victor D. Dinglas ${ }^{4,9}$, O. Joseph Bienvenu ${ }^{5,9}$, Ann M. Parker ${ }^{4,9}$, Ramona O. Hopkins ${ }^{6,7,8}$, Dale M. Needham ${ }^{1,4,9^{*}}$ and Karin J. Neufeld ${ }^{5,9}$

\section{Correction to: Crit Care \\ https://doi.org/10.1186/s13054-019-2553-z}

In the publication of this article [1], there is an error in the Abstract. This has now been included in this correction article.

The error in the abstract currently reads:

The IES-6 demonstrated internal consistency over multiple time points up to 5 years after ARDS (Cronbach's alpha $=0.96$; 95\% confidence interval (CI) 0.94 to 0.97 ).

It should instead read in the abstract:

The IES-6 demonstrated internal consistency over multiple time points up to 5 years after ARDS (Cronbach's alpha $=0.86$ to 0.91 ) and high correlation with the IES-R (0.96; 95\% confidence interval (CI): 0.94 to 0.97$)$.

\section{Author details}

'Department of Physical Medicine and Rehabilitation, Johns Hopkins School of Medicine, Baltimore, MD, USA. ${ }^{2}$ Department of Psychiatry and Behavioral Sciences, Johns Hopkins School of Medicine, Baltimore, MD, USA.

${ }^{3}$ Department of Biostatistics, Johns Hopkins Bloomberg School of Public Health, Baltimore, MD, USA. ${ }^{4}$ Division of Pulmonary and Critical Care Medicine, Johns Hopkins School of Medicine, Baltimore, MD, USA.

${ }^{5}$ Department of Psychiatry and Behavioral Sciences, Johns Hopkins School of Medicine, Baltimore, MD, USA. ${ }^{6}$ Department of Medicine, Pulmonary and Critical Care Division, Intermountain Medical Center, Murray, UT, USA. ${ }^{7}$ Center for Humanizing Critical Care, Intermountain Health Care, Murray, UT, USA. ${ }^{8}$ Neuroscience Center and Psychology Department, Psychology Department and Neuroscience Center, Brigham Young University, Provo, UT, USA.

${ }^{9}$ Outcomes After Critical IIIness and Surgery (OACIS) Group, Johns Hopkins School of Medicine, Baltimore, MD, USA.
Published online: 04 February 2020

\section{Reference}

1. Hosey MM, Leoutsakos JS, Li X, et al. Screening for posttraumatic stress disorder in ARDS survivors: validation of the impact of event Scale-6 (IES-6). Crit Care. 2019;23:276 https://doi.org/10.1186/s13054-019-2553-z.

The original article can be found online at https://doi.org/10.1186/s13054019-2553-z

* Correspondence: Dale.needham@jhmi.edu

'Department of Physical Medicine and Rehabilitation, Johns Hopkins School of Medicine, Baltimore, MD, USA

${ }^{4}$ Division of Pulmonary and Critical Care Medicine, Johns Hopkins School of Medicine, Baltimore, MD, USA

Full list of author information is available at the end of the article

(c) The Author(s). 2020 Open Access This article is distributed under the terms of the Creative Commons Attribution 4.0 International License (http://creativecommons.org/licenses/by/4.0/), which permits unrestricted use, distribution, and reproduction in any medium, provided you give appropriate credit to the original author(s) and the source, provide a link to the Creative Commons license, and indicate if changes were made. The Creative Commons Public Domain Dedication waiver (http://creativecommons.org/publicdomain/zero/1.0/) applies to the data made available in this article, unless otherwise stated. 